\title{
Variation In Speech Perception Scores Among Children with Cochlear Implants
}

\author{
J.Z. Sarant, P.J. Blamey, R.C. Dowell, G.M. Clark, and W.P.R. Gibson
}

\begin{abstract}
Objective: The objective of this study was to identify common factors affecting speech perception scores in children with cochlear implants.
\end{abstract}

Design: Speech perception data for 167 implanted children were collected at two cochlear implant centres in Melbourne and Sydney. The data comprised audition-alone scores on open-set word and sentence tests. Children were selected on the basis that they had a Nucleus 22-electrode cochlear implant. The average age of the children was $5 \mathrm{yr}$. Information was also collected about 12 factors that may have influenced speech perception scores for each child. Analysis of covariance was used to identify factors that significantly affected speech perception scores. Pearson pairwise correlation coefficients were also calculated for all factors analyzed.

Results: The analyses in this study identified factors that accounted for $51 \%, 34 \%$, and $45 \%$ of the variance in phoneme, word and sentence perception scores. Scores decreased by 1.4 to $2.4 \%$ per year of profound deafness prior to implantation. Children who normally use oral communication scored significantly higher than children normally using sign or simultaneous oral and sign communication. Children implanted in Sydney scored higher on average than children implanted in Melbourne.

Conclusions: The results show that a significant part of the variation in speech perception scores is systematically related to audiological and environmental factors for each child. The reasons for significant differences between children using different communication modes or from different clinics were not identified.

(Ear \& Hearing 2001;22;18-28)

More than 7000 children from age 1 to $18 \mathrm{yr}$ have been implanted around the world with the Nucleus cochlear implant (Dowell, Blamey, \& Clark, 1997). These children are currently using the speech processing schemes that are known to be appropriate for postlinguistically deafened adults. Until recently, it was not known whether these schemes were appropriate for facilitating the speech percep-

Bionic Ear Institute (J.Z.S.), Melbourne, Australia; Department of Otolaryngology (P.J.B., R.C.D., G.M.C.), University of Melbourne, Melbourne, Australia; and Sydney Children's Cochlear Implant Centre (W.P.R.G.), University of Sydney, Sydney, Australia. tion and language development of young children. It is now well-documented that many profoundly hearing-impaired children using the Nucleus cochlear implant receive significant open-set speech perception benefits from use of their device (Dawson et al., 1992; Geers \& Moog, 1994; Osberger, Chute, Pope, Kessler, Carotta, First, \& Zimmerman-Phillips, 1991; Osberger, Miyamoto, Zimmerman-Phillips, Lemink, Stroer, Firszt, \& Novak, 1991). Two recent studies, Dowell, Blamey, and Clark (1995, 1997), reported that 60 to $80 \%$ of implanted children achieved significant open-set word and sentence perception abilities. Therefore, it is reasonable to expect that the majority of profoundly deaf children who have a cochlear implant will achieve some degree of open-set speech perception. This represents a significant achievement, when it is considered that many of these children are congenitally profoundly deaf and have developed their auditory processing abilities entirely through the information provided by their cochlear implants.

Despite this degree of success, speech perception benefits for children with cochlear implants still vary over a wide range (Osberger, Miyamoto, Zimmerman-Phillips, Lemink, Stroer, Firszt, \& Novak, 1991; Staller, Beiter, Brimacombe, Mecklenburg, \& Arndt, 1991), with up to $15 \%$ of children showing very limited closed-set speech perception abilities (Dowell et al., 1995; Fryauf-Bertschy, Tyler, Kelsay, \& Gantz, 1992). It is therefore important to be able to identify those factors that contribute to a successful result after cochlear implantation, so that each child's chance of success is maximized, and so that a more informed decision can be made regarding implantation. Several factors are believed to contribute to variations in speech perception benefit for children. Children who were hearing-impaired from an early age, and who have had a long duration of deafness prior to implantation demonstrate poorer performance on speech perception tasks (Mecklenburg, 1988; Osberger, Chute, Pope, Kessler, Carotta, First, \& Zimmerman-Phillips, 1991; Osberger, Miyamoto, Zimmerman-Phillips, Lemink, Stroer, Firszt, \& Novak, 1991; Staller et al., 1991). It has also been suggested that children with a congenital hearing loss do not receive as much benefit from a cochlear implant as those with an acquired loss (Stark, 1991), and that the etiology of the hearing loss also affects 
speech perception (O'Sullivan, Ellul, Dowell, Pyman, \& Clark, 1997). Prelingually deafened children who are implanted at or after adolescence appear to have less potential for benefit from a cochlear implant than children implanted under the age of $10 \mathrm{yr}$ (Busby, Roberts, Tong, \& Clark, 1991; Snik, Makhdoum, Vermeulen, Brokx, \& Van den Broek, 1997; Tong, Busby, \& Clark, 1988; Zwolan, Reference Note 2). Although there are exceptions (Sarant, Cowan, Blamey, Galvin, \& Clark, 1994), congenitally hearing-impaired children implanted during adolescence have not generally achieved open-set speech perception with their implant alone (Chute, 1993; Dowell et al., 1991; Snik et al., 1997). A cochlear implant is of primary use to this group as a supplement to lipreading (Dawson et al., 1992). Educational placement and mode of communication, and the provision of appropriate auditory habilitation also influence speech perception benefits (Geers \& Moog, 1991). It is also clear that although we can make generalisations about speech perception performance potential for different groups of children, there will be many exceptions to these.

In addition to factors that can affect a child's potential to benefit from a cochlear implant, there are additional challenges with assessing young children that limit accuracy and reliability. It is problematic to assess speech perception benefits objectively at a word or sentence level with children who have a congenital profound hearing impairment and cannot read or write, as they usually have delayed, and often unintelligible, speech. Therefore, in evaluating some children it becomes a matter of the judgement of individual clinicians as to whether their verbal response is correct. Furthermore, in the process of perceiving speech, language knowledge is required. Therefore, in interpreting children's speech perception results, it should be remembered that there is a cognitive load in speech perception testing that varies between children depending on their level of competence in language, and that this will introduce a degree of variability into results that is difficult to quantify (Sarant, Blamey, Cowan, $\&$ Clark, 1997). For these reasons, speech perception scores on various measures have been categorised in some previous studies of large groups of children (Dowell et al., 1995, 1997). Thirty young children whose language skills were clearly inadequate for open-set perception testing were excluded from the present study. These exclusions do not guarantee that the speech and language skills of the other 165 children will have no effect on their speech perception results. This should be considered as a possible uncontrolled variable in the analyses of this study.

The aim of this study was to identify common factors affecting speech perception scores in children with cochlear implants.

\section{Methods}

\section{Subjects}

Data for a total of 167 children were collected at the Royal Victorian Eye and Ear Hospital Cochlear Implant Clinic in Melbourne and at the Children's Cochlear Implant Centre in Sydney. All subjects were implanted with the Nucleus 22-electrode cochlear implant. There were approximately $30 \mathrm{im}$ planted children in Melbourne and Sydney who could not be included in this study, as no open-set speech perception data were available. This is because clinicians in both clinics decided that their language skills were insufficient for open-set speech perception testing. These children comprise approximately $15 \%$ of the total number of implanted children in Melbourne and Sydney (197), which is consistent with some previously reported figures on the percentage of implanted children who show very limited open-set speech perception ability (Dowell et al., 1995, 1997).

\section{Speech Perception Evaluations}

At the time of the analysis (April, 1998), open-set speech perception data were obtained from the most recent speech perception evaluations administered by staff at the Melbourne and Sydney Clinics. Speech perception test materials were presented by clinicians using live-voice, at a distance of approximately 1 meter, and at an intensity of approximately $70 \mathrm{~dB}(\mathrm{~A})$. Most children gave their responses orally, although some who were older wrote their responses. Feedback on performance was not provided throughout test procedures, and no repetition of stimuli was allowed. In Melbourne, evaluations were recorded on videotape and were later scored by two clinicians independently. These scores were averaged. In Sydney, evaluations were also videotaped, but responses were scored on-line by the clinician evaluating the child, and were not coscored by another clinician. All speech perception data used in this study were collected in the audition-alone condition, without lipreading.

Both Clinics used the Bamford-Kowal-Bench (BKB/A) Sentence test (Bench, Bamford, Wilson, \& Clifft, 1979) to assess open-set speech perception in running speech. Each BKB/A list consisted of 16 simple sentences that contained 50 key words. The test was scored according to the number of key words correct in each list. The clinics differed with regard to their choice of word test. The Melbourne Clinic used Phonetically Balanced Kindergarten 
TABLE 1. Categorical factors.

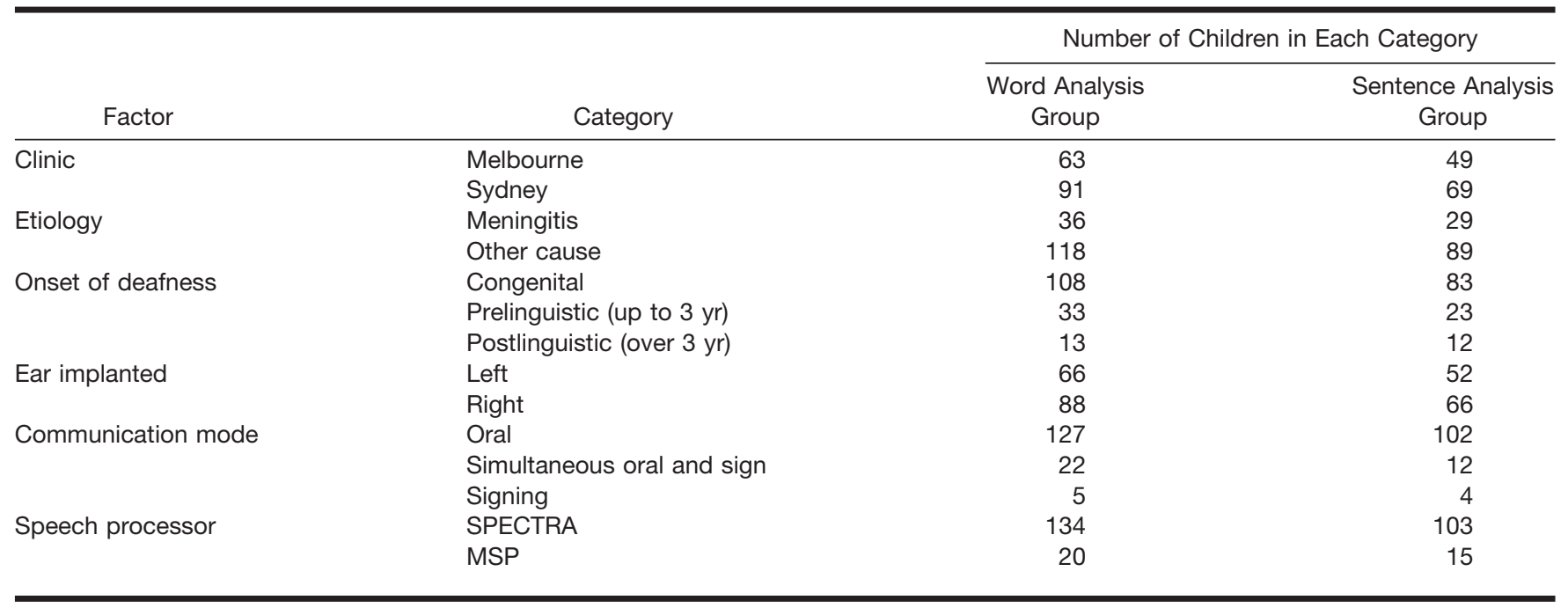

(PBK) Word Lists (Haskins, Reference Note 1) to assess open-set speech perception at a word and phoneme level. This test consists of 50 phonetically balanced words that are in the vocabulary of most 5 -yr-old children with normal hearing. Half lists of 25 words were presented. These were scored both according to the number of phonemes correct in each word (phoneme score) and the number of whole words correct in each list (word score). In Sydney, performance at word and phoneme levels was assessed using (CNC) Word Lists (Peterson \& Lehiste, 1962). Full lists of 50 words were administered, and were scored phonemically and according to the number of whole words correct per list.

The reliability of the clinicians' scoring of evaluations was assessed using data from another study that currently involves most of the children from the present study (both Melbourne and Sydney) and all of the clinicians (Blamey et al., 1998). For BKB Sentences, the standard deviation of intertranscriber differences across 160 lists transcribed by two people in both conditions (A and AV) was 5.7\%. This can be compared with an inter-list variability of $10.1 \%$ across 126 pairs of BKB Sentence lists both presented to the same child in the same condition and transcribed by the same transcriber. The intertranscriber difference for CNC Words across 171 lists transcribed by two transcribers was $3.0 \%$ for phoneme scores and $6.3 \%$ for word scores. The inter-list variability was $5.9 \%$ for phonemes and $10.8 \%$ for words for 127 pairs of lists. These figures allow us to estimate the percentage of the variance arising from random variation between transcriber and test-retest reliability in the analyses below to be 7.6\% for BKB Sentences, $14.2 \%$ for CNC Words and $13.0 \%$ for CNC phonemes.

\section{Results}

\section{Factors}

There were 118 children with scores on BKB/A Sentences, and 154 children with scores on a monosyllabic word test (either CNC or PBK Words). Since different groups of children were involved, separate analyses were done for words and sentence scores. Data on six categorical factors and six numerical factors that may have influenced speech perception scores were collected for each child. These factors are listed in Tables 1 and 2, respectively.

Meningitis was separated from other etiologies because previous studies have suggested that adults with meningitis tended to have lower scores (Battmer, Gupta, Allum-Mecklenburg, \& Lenarz, 1995; Dorman, Hannley, Dankowski, Smith, \& McCandless, 1989). Most children used the SPECTRA-22 speech processor with SPEAK processing strategy, although a few used the older MSP with Multipeak speech processing strategy. Chi-squared analyses were used to test associations between pairs of categorical variables in Table 1 . These showed that Etiology was significantly associated with Onset of deafness $(p<0.001)$, as one would expect from the fact that meningitis was not a congenital cause of deafness. Communication mode was significantly associated with Clinic. This is thought to be a consequence of different candidate selection criteria in the two clinics. It should be noted that the Clinic factor covers a variety of procedural differences with regard to selection, management, and assessment of children (including the different word tests used).

In Table 2, "No of speech frequencies" refers to the number of audiological frequencies with aided thresholds within the $70 \mathrm{~dB}$ SPL speech spectrum 
TABLE 2. Numerical factors.

\begin{tabular}{|c|c|c|c|c|c|}
\hline \multirow[b]{2}{*}{ Factor } & \multirow[b]{2}{*}{ Range } & \multicolumn{2}{|c|}{ Word Analysis Group } & \multicolumn{2}{|c|}{$\begin{array}{c}\text { Sentence Analysis } \\
\text { Group }\end{array}$} \\
\hline & & Mean & SD & Mean & $\mathrm{SD}$ \\
\hline Duration of deafness & $0.2-13.7 \mathrm{yr}$ & 4.5 & 3.2 & 4.8 & 3.4 \\
\hline Test age & $2.8-19.8 \mathrm{yr}$ & 9.2 & 3.5 & 9.9 & 3.4 \\
\hline Implant experience & $0.1-10.6 \mathrm{yr}$ & 3.9 & 2.1 & 4.3 & 2.1 \\
\hline
\end{tabular}

prior to cochlear implantation. The speech spectrum was based on an analysis of spoken English by an Australian speaker (Byrne, 1977). According to this analysis, the speech spectrum is between 45 and 75 $\mathrm{dB}$ SPL at $250 \mathrm{~Hz} ; 47$ and $77 \mathrm{~dB}$ SPL at $500 \mathrm{~Hz} ; 40$ and $70 \mathrm{~dB}$ SPL at $1000 \mathrm{~Hz}$; and 34 and $63 \mathrm{~dB}$ SPL at $2000 \mathrm{~Hz}$. Duration of deafness is the time between the onset of profound deafness and the date of cochlear implantation. Tables 3 and 4 show Pearson pairwise correlation coefficients for the numerical factors for the two groups of children. The pairs of variables that showed significant correlation were similar across the two groups. This is to be expected because of the considerable overlap of the two groups. Age at implantation, Duration of deafness, and Test age were highly correlated. Duration of deafness was used in the regression analyses below, leaving out Age at implantation and Test age to avoid potential ambiguity in the results. It should be noted that the majority of children in this study were congenitally profoundly deaf, so that Duration of deafness is equivalent to Age at implantation in most cases. Similarly, Test age is equivalent to
Duration of deafness plus Implant experience in most cases. The additional correlations between No of speech frequencies and Duration of deafness for both groups, and between Implant experience and No of speech frequencies and No of electrodes for the sentence analysis group are discussed below.

\section{CNC and PBK Words Combined Results-Phoneme Analysis}

Speech perception scores were analyzed using analysis of covariance with the general linear model of Minitab Version 12 (Ryan \& Joiner, 1994). A step-wise procedure was used in which factors were added successively to the analysis until no further factors with a significant effect could be found. Five factors significantly affected phoneme scores on the PBK and CNC Word tests. These were Duration of deafness $(p<0.001)$, Implant experience $(p<0.05)$, Communication mode $(p<0.001)$, Clinic $(p<0.001)$ and Speech processor $(p<0.01)$. These five factors accounted for $51 \%$ of the variance in this sample. Average phoneme scores decreased by $1.4 \%$ per year

TABLE 3. Pearson pairwise correlations of factors that could significantly affect speech perception scores on Sentences. Those factors that were significant $(p<0.01)$ are highlighted in bold text.

\begin{tabular}{|c|c|c|c|c|c|}
\hline & Age at Implant & $\begin{array}{l}\text { Duration of } \\
\text { Deafness }\end{array}$ & Test Age & $\begin{array}{c}\text { Implant } \\
\text { Experience }\end{array}$ & $\begin{array}{l}\text { Number of Speech } \\
\text { Frequencies }\end{array}$ \\
\hline Duration of deafness & 0.839 & & & & \\
\hline Implant experience & -0.249 & -0.277 & 0.379 & & \\
\hline Number of speech frequencies & 0.370 & 0.561 & 0.178 & -0.286 & \\
\hline Number of electrodes & 0.065 & 0.117 & -0.090 & -0.247 & 0.216 \\
\hline
\end{tabular}

TABLE 4. Pearson pairwise correlations of factors that could significantly affect speech perception scores on Words. Those factors that were significant $(p<0.01)$ are highlighted in bold text.

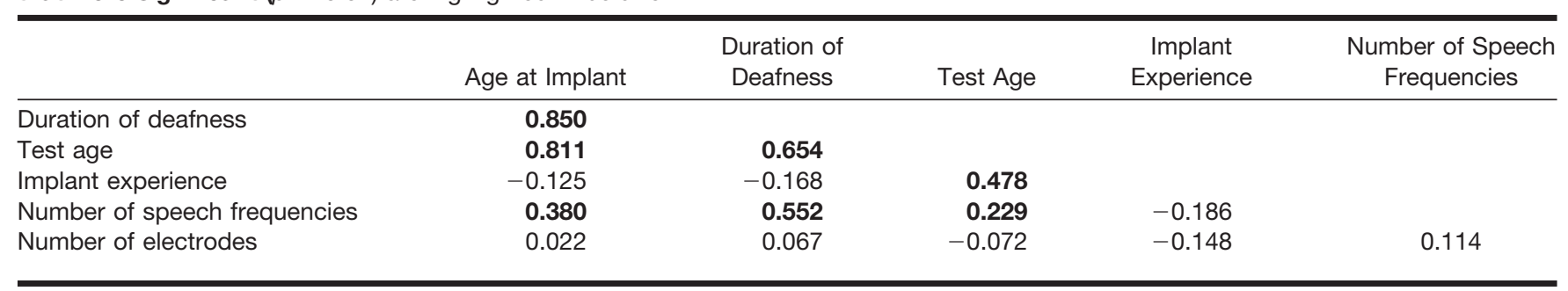




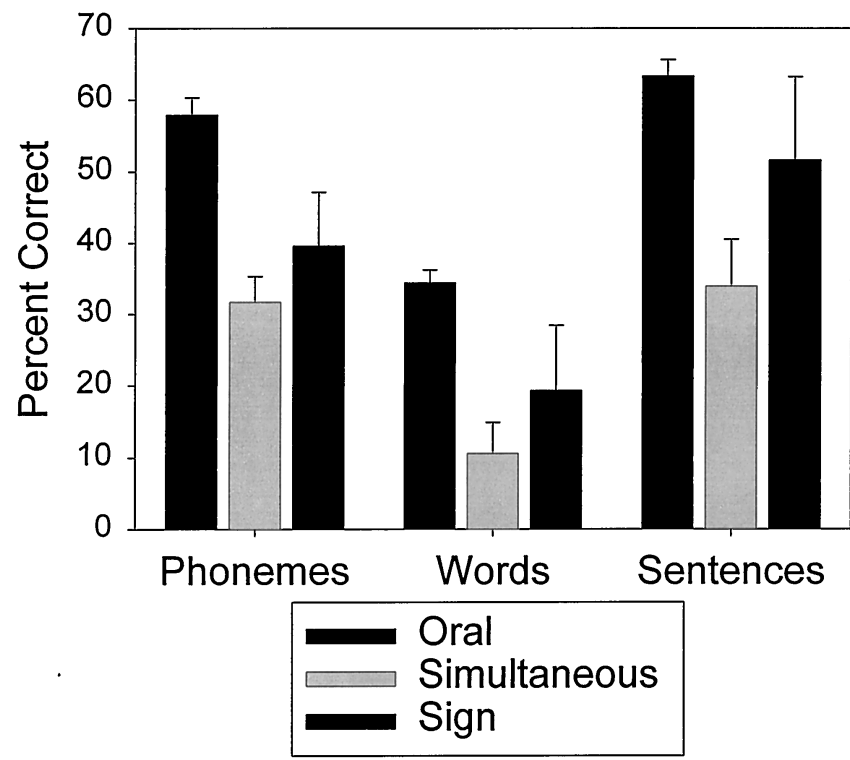

Figure 1. Mean phoneme, word, and sentence scores for children using three communication modes. The error bars indicate the standard error of the mean for each group.

of profound deafness, and increased by $1.6 \%$ per year of implant experience. Figures 1 and 2 show least squares mean phoneme scores for children classified by Communication mode, Clinic, and Processor, respectively. The least squares means are calculated by adjusting each child's data to the mean value of Duration of deafness and Implant experience.

\section{CNC and PBK Words Combined Results-Word Analysis}

Duration of deafness $(p<0.001)$, and Implant experience $(p<0.05)$ also significantly affected word scores on the PBK and CNC Word tests. Average scores decreased by $1.9 \%$ per year of profound deafness, and increased by $1.7 \%$ per year of Implant experience. As with the phoneme analysis, Communication mode $(p<0.001)$, and Clinic $(p<0.001)$ significantly affected word scores (see Figs. 1 and 2). Children with higher numbers of aided thresholds in the speech range also tended to score better on words, by about $2.5 \%$ per threshold. These four factors accounted for $34 \%$ of the total variance.

\section{BKB/A Sentences}

As with the Word and Phoneme analyses, analysis of covariance on BKB/A Sentence scores showed Duration of deafness $(p<0.001)$, Communication mode $(p<0.001)$ and Clinic $(p<0.001)$ to be factors that significantly affected speech perception scores. Once again, those children with a shorter Duration of deafness achieved significantly higher scores,

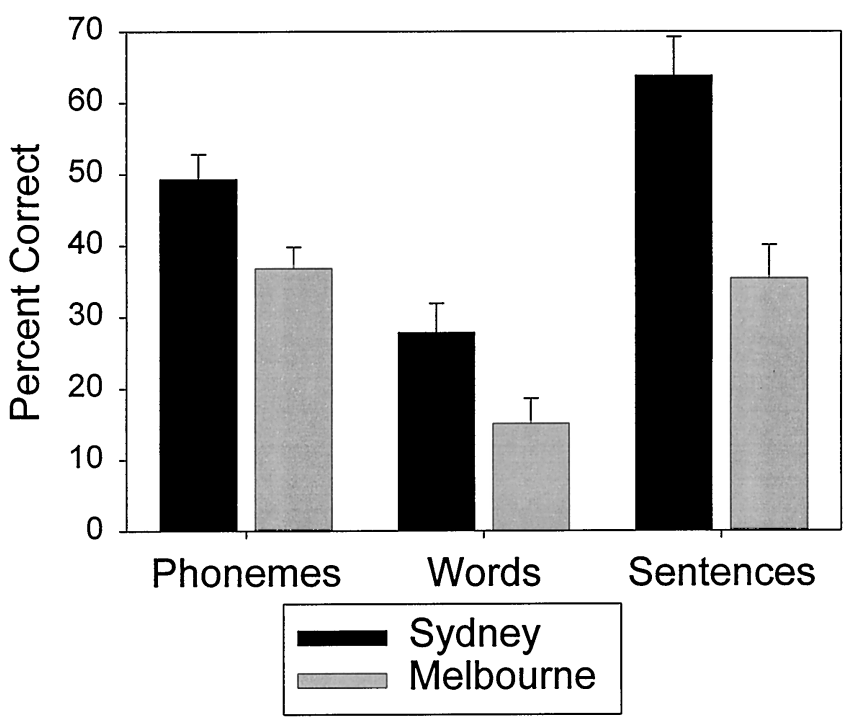

Figure 2. Mean phoneme, word, and sentence scores for children from the two clinics. The error bars indicate the standard error of the mean for each group.

with average scores decreasing by $2.4 \%$ per year of profound deafness. Figures 1 and 2 show least squares mean BKB/A scores for children classified by Communication mode and Clinic, respectively. The three factors accounted for $45 \%$ of the total variance in the sample.

\section{Comparison of Sydney and Melbourne Groups}

It may have been reasonable to expect a difference in word scores between the two clinics, as a different word test was used in each, and there may be differences in terms of difficulty between the tests However, it was unexpected that the Melbourne/ Sydney factor should be so highly significant in the analysis of sentence scores, as the same test was used in both clinics. Therefore, the differences between the two populations of children were examined further.

The average age at implantation for the Sydney group of children was $5.6 \mathrm{yr}$ for both word and sentence data. The average ages at implantation for the Melbourne group were 5.2 yr (word data) and 5.6 yr (sentence data). Two-sample $t$-tests showed that there was no significant difference in age at implantation between the two populations of children $(p=$ $0.44)$.

The average number of electrodes in a child's map for the Sydney group was 19.5 for both word and sentence data. The average numbers of electrodes in a child's map for the Melbourne group were 18.8 (word data) and 18.7 (sentence data). A two-sample $t$-test showed that there was no significant differ- 
ence between numbers of electrodes in Sydney versus Melbourne children's maps $(p=0.063)$.

Of the Sydney population of children, for the word data $26 \%$ had preoperative aided thresholds in the $70 \mathrm{~dB}$ SPL speech range at $2 \mathrm{kHz}$, and for the sentence data $27 \%$ had preoperative aided thresholds in the $70 \mathrm{~dB}$ SPL speech range at $2 \mathrm{kHz}$. However, only $6 \%$ of the Melbourne population (both word and sentence data) had aided hearing in the 70 $\mathrm{dB}$ SPL speech range at this frequency. A Chisquare test showed that a significantly greater proportion of Sydney children had aided hearing at 2 $\mathrm{kHz}$ than did the Melbourne population $\left(\mathrm{Chi}^{2}=\right.$ $9.72 ; p<0.05, \mathrm{df}=1$ ).

With regard to communication/educational method, $7 \%$ and 6\% (word and sentence data, respectively) of the Sydney population used simultaneous oral and sign communication and 93\% and 94\% (word and sentence data, respectively) used oral communication. In Melbourne 25\% of children used simultaneous oral and sign communication, $8 \%$ used signing and $67 \%$ used oral communication for word data. For sentence data, 16\% used simultaneous oral and sign communication, $8 \%$ used signing and $76 \%$ used oral communication. Overall, the Sydney population had a significantly greater proportion of children using oral communication than the Melbourne population $\left(\mathrm{Chi}^{2}=19.23 ; p<0.05\right.$, $\mathrm{df}=1)$.

\section{Discussion}

\section{Significant Factors}

Duration of deafness was found to significantly affect speech perception scores on all assessments in this study. As mentioned previously most of the children in this study were congenitally profoundly deaf, therefore this factor is equivalent to age at implantation for these children. Children whose duration of profound deafness was shorter demonstrated significantly higher speech perception scores on both tests than those who had a long period of profound deafness prior to cochlear implantation. This result has previously been reported for both adults (Blamey et al., 1992, 1996; Blamey, 1997; Gantz, Woodworth, Knutson, Abbas, \& Tyler, 1993) and children (Dowell et al., 1995, 1997). It is consistent with physiological sensory deprivation studies that have demonstrated that in the absence of auditory stimulation, neural structures show a failure to mature and can degenerate (Nadol, Young, \& Glynn, 1989; Shepherd, Hartman, Heid, Hardie, \& Klinke, 1997; Webster \& Webster, 1977, 1979). In addition, some measures of temporal resolution have been shown to be sensitive to the effects of auditory deprivation (Busby, Tong, \& Clark, 1993a, 1993b).
Therefore, children who are implanted reasonably soon after the onset of profound deafness, or when young if congenitally deaf, have a better chance of doing well perceptually than those who are not implanted for some time after diagnosis of hearing loss.

Significant differences were found between children grouped according to Communication mode (oral, simultaneous, or sign). Oral communicators scored significantly higher than the other two groups. Other researchers have also reported this finding (Berliner, Tonokawa, Brown, \& Dye 1988; Dowell et al., 1995, 1997; Quittner \& Steck, 1991). Significant differences were also found between children implanted in the Sydney clinic and those implanted in Melbourne. It is not possible to conclude unambiguously from these results that oral communication promotes better speech perception skills than sign or simultaneous communication, or that the methods used in Sydney are more effective than those in Melbourne, although these are plausible potential reasons for the results. To prove a causal relationship like this, we would have to satisfy one of the following three conditions: a) that the children in each subgroup were chosen randomly from the same population of children with impaired hearing; b) that the children in each subgroup were matched on all relevant variables; or c) that the quantitative effects of all relevant variables were known so that differences between the groups could be allowed for in the comparison. Unfortunately (taking a statistical view rather than a clinical view), cochlear implant clinics do not determine implant candidature randomly, and communication mode is usually determined in a way that would make it difficult to find a sizeable group of children with matched characteristics. For example, deaf children of hearing parents in Australia tend to be placed in an oral stream first, and are moved into a signing environment only if they are making poor progress relative to other deaf children in the oral stream. Clearly, conditions a) and b) were not satisfied in this study, leaving $\mathrm{c}$ ). The inclusion of a wide variety of factors in the analyses of covariance in this study makes allowance for differences between the subgroups on these measures, but there may be other relevant factors that were not included in this study, such as IQ and speech production ability. Speech production ability may be particularly relevant to the comparison of the communication modes. If children relying on sign are less intelligible than children using oral communication, they may perceive words or sentences correctly and produce them incorrectly, thus reducing their "speech perception" score under the conditions used in this study.

Given the caveats in the previous paragraph, we 
can conclude that either the normal use of oral communication produces a better speech perception outcome with a cochlear implant than the use of simultaneous or sign communication, or there are significant variables not considered in this study that were confounded with communication mode. Nonverbal IQ, the presence of handicaps in addition to impaired hearing, and speech production ability are obvious variables that need to be considered in future research of this type. Interestingly, there was no significant association in this study group between the use of sign and the number of aided hearing thresholds in the speech range $(\mathrm{Chi} 2=1.3$, $\mathrm{df}=4, p=0.862$ ). It was not possible to examine the relationship between preoperative speech perception and communication mode in this study, as data on preoperative speech perception were not available. Communication mode was significantly correlated with the type of speech processor used, but the difference between processors was explicitly allowed for in the analyses.

Similarly, we can conclude that either the candidate selection, implantation, management and assessment methods used in Sydney produce better speech perception outcomes than those used in Melbourne, or there are significant variables not considered in this study that were confounded with the Clinic variable. The comparison of children in the Sydney and Melbourne groups shows that they do differ significantly in the amount of preoperative residual hearing and communication mode, probably because of differences in implant candidate selection procedures. These factors were included in the analyses, but other measures related to candidate selection, based on cognitive and/or motor delay, were not included in this study because of a lack of consistent data. A recent study showed that a reasonably large number of children in Melbourne with cognitive or motor delay were acquiring openset speech perception, but at a slower rate than other children (Pyman, Blamey, Lacy, Clark, \& Dowell, 2000). Assessment differences between the clinics include the use of CNC Words in Sydney and PBK Words in Melbourne, together with the different scoring procedures described in the method section. Programming methodological differences could also exist between the two clinics. An additional potential cause of perceptual differences between the two clinics could be that the two populations of children differ significantly with regard to their language abilities, which have been shown to significantly affect speech perception performance (Sarant et al., 1997). Differences in language abilities between the two groups of children could be attributed to the fact that they have attended school in different state school educational systems, and these may differ with regard to both teaching practices used and their success.

Duration of implant experience contributed significantly to higher speech perception scores for word and phoneme analyses. This result has also been reported by other researchers for both adults and children (Blamey et al., 1996; Dowell \& Cowan, 1997; Quittner \& Steck, 1991), and it seems logical that with increasing experience, children would become better able to use the auditory information provided by the cochlear implant. Although it has been shown that auditory skills in children continue to improve over a period of many years after implantation (Gantz, Tyler, Woodworth, Tye-Murray, \& Fryauf-Bertschy, 1994; Snik et al., 1997), it is possible that there is a length of time beyond which extra experience does not make a significant difference, as is the case for adults (Dorman, Dankowski, McCandless, Parkin, \& Smith, 1990). However, other factors that are not perceptual in nature, such as concentration abilities and language skills, should facilitate further improvements over time.

Children who used a SPECTRA speech processor as opposed to an MSP achieved higher phoneme scores on the word tests. This result is not surprising, given that the newer SPECTRA processor (incorporating the use of the SPEAK strategy) presents more speech information at a faster rate than does the MSP (McKay, Vandali, McDermott, \& Clark, 1994). Studies comparing the speech perception of children with both strategies that show that overall, users of the SPECTRA are able to use this extra information to achieve significantly higher scores with SPEAK than with MPEAK (Cowan et al., 1995; Sehgal, Kirk, Svirsky, \& Miyamoto, 1998).

Several researchers have found no significant correlation between preoperative hearing thresholds and postoperative speech perception performance in adults (Blamey et al., 1992; Gantz et al., 1993). In this study, children with more preoperative hearing did had higher word scores on average than those with fewer aided thresholds in the speech range. Others have found preoperative aided hearing to be a factor that significantly affected speech perception (Dowell et al., 1995, 1997; Dowell \& Cowan, 1997; Parkin, Stewart, \& Dankowski, \& Haas, 1989). As the survival of neural elements has been shown to be affected by sound deprivation, it would seem reasonable that maintenance of auditory stimulation between the onset of the profound hearing loss and cochlear implantation would perhaps protect the auditory system to some degree from degeneration due to lack of auditory stimulation. 


\section{Nonsignificant Factors}

Age at onset of profound deafness has been reported to influence speech perception performance in children from birth up to adolescence, at which time most adult language and auditory memories of speech have been established (Lehnhardt \& Aschendorff, 1993). Two studies have reported that children with progressive hearing losses achieve significantly higher speech perception scores than those whose loss was congenital or occurred early in life (Dowell et al., 1997; Osberger, Miyamoto, Zimmerman-Phillips, Lemink, Stroer, Firszt, \& Novak, 1991). These results are explained by the fact that children whose onset of hearing loss occurs later in life have usually had sufficient hearing to develop a language base and auditory memory of speech that will facilitate effective use of the auditory signal provided by the cochlear implant. It has also been reported that children with congenital and very early acquired deafness show comparable levels of speech perception performance, as the hearing loss for both groups is prelingual in nature (Dowell \& Cowan, 1997; Miyamoto, Osberger, Robbins, Myres, \& Kessler, 1993; Somers 1991). In this study, age at onset of profound deafness was not found to affect speech perception scores significantly on any test. This result can be explained further when the characteristics of the children who were assessed are considered. As most of the children in this study had either a congenital or prelingual onset of profound deafness (only four children had a progressive loss), the age at onset of deafness is almost equivalent to the duration of deafness, which significantly affected speech perception scores. As mentioned previously, the analyses used in this study do not yield a clear answer as to which variable is the significant one when variables are highly correlated. When both of these factors were included in the initial analysis, duration of deafness was chosen as the dominant influence because it showed a more significant effect than age at onset of deafness. If duration of deafness were to be excluded from the analysis, age at onset would in all likelihood show a significant effect.

Another factor that was seen to be highly correlated with duration of deafness in this study was age at implantation. In view of the current practice of implanting children as soon as possible after diagnosis, and the fact that most of the children in this study were profoundly hearing-impaired prelingually, once again it is reasonable to conclude that for many of these children, age at implantation was close to the onset of deafness. For many children, it was almost equivalent to the duration of profound deafness. Given this, as for age at onset of profound deafness, it is not surprising that the effect of age at implantation could not be separated from that of duration of deafness in this study. It has been reported, however, that if the onset of deafness is early, children who are implanted immediately after diagnosis achieve significantly higher speech perception scores than those who are implanted after many years of profound deafness (Mecklenburg, 1988; Osberger, Chute, Pope, Kessler, Carotta, First, \& Zimmerman-Phillips, 1991). Although this has not been addressed in the current study, other researchers have also reported that children implanted around or after adolescence reach a plateau of performance relatively quickly (Snik et al., 1997).

Etiology of hearing loss has previously been considered as a factor that may influence speech perception scores, and various studies have yielded mixed results. Studies of adults have reported a range of etiologies as being influential, such as Meniere's disease (Blamey, 1997) and otosclerosis (Blamey et al., 1992). There is also evidence that etiologies such as meningitis produce different degrees of survival of some neural elements, such as ganglion cells (Nadol et al., 1989). Intraoperative measures of electrically evoked auditory nerve compound action potentials obtained by Gantz, Brown, and Abbas (1994) suggested that there are differences in nerve function between patients with congenital hearing losses and those deafened by meningitis. The meningitis group demonstrated shallower amplitude growth functions and slower cochlear nerve recovery, both of which have been correlated with speech perception performance in adults (Gantz, Brown, \& Abbas, 1994). Differences in stapedius reflexes have also been found between congenitally deaf children and those with a meningitic etiology (Van den Borne, Snik, Mens, Brokx, \& Van den Broek, 1996). In some studies, adult meningitic implant users have demonstrated significantly poorer speech perception scores than implant users with other etiologies of hearing loss (Battmer et al., 1995; Dorman et al., 1989). Despite the evidence to suggest physiological differences between meningitic and other children, the results of this study demonstrated no significant differences in speech perception performance between these two groups of children. Others have also not found etiology to be a significant factor affecting speech perception (Dorman et al., 1990; Gantz et al., 1993; Parkin et al., 1989). A further factor that was not found to significantly affect speech perception results in this study was the implanted ear (left or right).

The number of functional electrodes in children's maps was not found to significantly affect perception scores in this study. The literature shows that results are varied with regard to this factor's effect on 
speech perception results. In a study of 100 children from Melbourne and Sydney, Dowell et al. (1995) reported that electrode numbers did not significantly affect speech perception scores. However, it has been thought that deeper insertions and therefore greater electrode numbers increase the amount of information that can be presented and give a lower and more "natural" pitch to speech sounds (Tong \& Clark, 1985). Electrode numbers have been found to significantly affect speech perception scores for adults in some studies (Blamey et al., 1992; Geier $\&$ Norton, 1992). However, determining whether number of electrodes is a significant factor is difficult, as there are relatively few children who have either small or medium numbers of electrodes in their map.

\section{Other Possible Factors}

The analyses in this study found factors that accounted for $51 \%$ of the variance in phoneme recognition scores. We also estimated that $19.5 \%$ of the total variance arose from inter-transcriber and inter-list differences. This leaves $31.5 \%$ of the variance in scores unaccounted for. As mentioned previously, the percentages of variance unaccounted for in the $\mathrm{BKB}$ sentence and CNC Words analyses were higher. It is therefore highly likely that other factors that contribute to variability in speech perception scores were not considered in this study. These could include influences in the home environment of children such as parental expectations and the amount of time they spend conversing with members of their family. There are many potential factors in the school environment, in which children spend an enormous amount of time, that could influence their speech perception abilities. These could include teaching methods used, time spent integrated into a normal classroom, and time spent on individual instruction. Significant factors could also include additional cognitive disabilities such as limited short-term memory span, or physical disabilities such as cerebral palsy that could compromise speech production (and therefore speech perception scores using verbal responses). As mentioned previously, language disabilities have also been shown to significantly affect speech perception scores in children (Sarant et al., 1997), but these were not assessed in this study. Maintenance of a consistent and useful auditory input would also seem likely to affect children's abilities to use their cochlear implant to perceive speech. Practical experience has shown that this can vary greatly between children, as young children may not report device failure or hardware problems, and these can be especially difficult to detect if they are intermittent. Younger children are also usually the roughest in their play, and are therefore more likely to be in the situation of breaking parts of their hardware than older children. In a busy school environment, the fact that a child is "off the air" may not be noticed for some time, especially since deaf children are usually adept at reading visual clues about what is going on and conforming to group activities using this information. Also, consistent device use must be maintained, which is not always the case.

Finally, it must also be considered that speech perception performance in children is to some degree unpredictable, given the potential for the many relationships that could exist between all of the variables in a hearing-impaired child's life.

\section{Conclusion}

The analyses in this study identified factors that accounted for up to $51 \%$ of the variance in speech perception scores. The significant factors were duration of profound deafness prior to implantation, duration of implant experience, mode of communication, clinic location, type of speech processor used, and number of preoperatively aided thresholds in the speech range. It is well-documented that many children implanted with the Nucleus cochlear implant use their device effectively to perceive speech, learn language and monitor their speech production. However, there are still many unanswered questions regarding profoundly deaf children and their potential to benefit from a cochlear implant. The upper limits of how well these children can learn to use the cochlear implant to perceive speech and develop language are still unknown. Although we have identified several factors which affect speech perception in children, their interrelationships, and the degree to which each individual factor influences the final outcome, are not clearly defined.

\section{ACKNOWLEDGMENTS:}

The authors would like to express their gratitude to the children and staff of the Royal Victorian Eye and Ear Cochlear Implant Clinic in Melbourne and the Children's Cochlear Implant Centre in Sydney. We also gratefully acknowledge the financial support of the National Health and Medical Research Council of Australia.

Address for correspondence: Julia Z. Sarant, BSc, Dip Aud, Ph.D., The Bionic Ear Institute, 384-388 Albert Street, East Melbourne, Victoria 3002, Australia.

Received September 2, 1999; accepted July 26, 2000

\section{REFERENCES}

Battmer, R. D., Gupta, S. P., Allum-Mecklenburg, D. J., \& Lenarz, T. (1995). Factors influencing cochlear implant percep- 
tual performance in 132 adults. Annals of Otology Rhinology and Laryngology, 104 (Part 2, Suppl. 166), 185-187.

Bench, J., Bamford, J.M., Wilson, I. M., \& Clifft, L. (1979). A comparison of the BKB sentence lists for children with other speech audiometry tests. Australian Journal of Audiology, 1, $61-66$.

Berliner, K. I., Tonokawa, L. L., Brown, C. J., \& Dye, L. M. (1988). Cochlear implants in children: Benefits and concerns. American Journal of Otology, 9 (Suppl.), 86-92.

Blamey, P. J. (1997). Are spiral ganglion cell numbers important for speech perception with a cochlear implant? American Journal of Otology, 18, S11-S12.

Blamey, P. J., Arndt, P., Bergeron, F., Bredberg, G., Brimacombe, J., Facer, G., Larky, J., Lindstrom, B., Nedzelski, J., Peterson, A., Shipp, D., Staller, S., \& Whitford, L. (1996). Factors affecting auditory performance of postlinguistically deaf adults using cochlear implants. Audiology and Neuro-Otology, 1, 293306.

Blamey, P. J., Pyman, B. C., Gordon, M., Clark, G. M., Brown, A. M., Dowell, R. C., \& Hollow, R. D. (1992). Factors predicting postoperative sentence scores in postlingually deaf adult cochlear implant patients. Annals of Otology, Rhinology and Laryngology, 101, 342-348.

Blamey, P. J., Sarant, J. Z., Serry, T., Wales, R., James, C., Barry, J., Clark, G. M. C., Wright, M., Tooher, R., Psarros., C., Godwin, G., Rennie, M., \& Meskin, T. (1998). Speech perception and spoken language in children with impaired hearing. Proceedings of the Fifth International Conference on Spoken Language Processing, Volume, 6, (pp. 2615-2618.).

Busby, P. A., Roberts, S. A., Tong, Y. C., \& Clark, G. M. (1991). Results of speech perception and speech production training for three prelingually deaf patients using a multiple-electrode cochlear implant. British Journal of Audiology, 25, 291-302.

Busby, P. A., Tong, Y. C., \& Clark, G. M. (1993a). Electrode position, repetition rate, and speech perception by early- and late-deafened cochlear implant patients. Journal of the Acoustical Society of America, 93, 1058-1067.

Busby, P. A., Tong, Y. C., \& Clark, G. M. C. (1993b). The perception of temporal modulations by cochlear implant patients. Journal of the Acoustical Society of America, 94, 124131.

Byrne, D. (1977). The speech spectrum-some aspects of its significance for hearing aid selection and evaluation. British Journal of Audiology, 11, 40-46.

Chute, P. M. (1993). Cochlear implants in adolescents. Advances in Otorhinolaryngology, 48, 210-215.

Cowan, R. S. C., Brown, C., Whitford, L. A., Galvin, K. L., Sarant, J. Z., Barker, E. J., Shaw, S., King, A., Skok, M. C., Seligman, P. M., Dowell, R. C., Gibson, W. P. R., \& Clark, G. M. (1995). Speech perception in children using the advanced SPEAK speech-processing strategy. Annals of Otology, Rhinology, and Laryngology, 104 (Suppl. 166), 318-321.

Dawson, P. W., Blamey, P. J., Rowland, L. C., Dettman, S. J., Clark, G. M., Busby, P. A., Brown, A. M., Dowell, R. C., \& Rickards, F. W. (1992). Cochlear implants in children, adolescents, and prelinguistically deafened adults: speech perception. Journal of Speech and Hearing Research, 35, 401-417.

Dorman, M. F., Dankowski, K., McCandless, G., Parkin, J. L., \& Smith, L. (1990). Longitudinal changes in word recognition by patients who use the Ineraid cochlear implant. Ear and Hearing, 11, 455-459.

Dorman, M. F., Hannley, M. T., Dankowski, K., Smith L., \& McCandless, G. (1989). Word recognition by 50 patients fitted with the Symbion multichannel cochlear implant. Ear and Hearing, 10, 44-49.

Dowell, R. C., Blamey, P. J., \& Clark, G. M. C. (1995). Potential and limitations of cochlear implants in children. Annals of
Otology, Rhinology and Laryngology, 104 (Part 2, Suppl. 166), 324-327.

Dowell, R. C., Blamey, P. J., \& Clark, G. M. (1997). Factors affecting outcomes in children with cochlear implants. In G. M. Clark (Ed.), Cochlear implants: XVI World Congress of Otorhinolaryngology, Head and Neck Surgery (pp. 297-303). Bologna: Monduzzi Editore.

Dowell, R. C., \& Cowan, R. S. C. (1997). Evaluation of benefit: Infants and children. In G. M. Clark, R.S.C. Cowan, \& R. C. Dowell (Eds.), Cochlear implantation for infants and children—advances (pp. 205-222). San Diego: Singular Publishing Group Inc.

Dowell, R. C., Dawson, P. W., Dettman, S. J., Shepherd, R. K., Whitford, L., Seligman, P. M., \& Clark, G. M. (1991). Multichannel cochlear implantation: a summary of current work at the University of Melbourne. The American Journal of Otology, 12 (Suppl.), 137-143.

Fryauf-Bertschy, H., Tyler, R. S., Kelsay, D. M., \& Gantz, B. J. (1992). Performance over time of congenitally deaf and postlingually deafened children using a multichannel cochlear implant. Journal of Speech and Hearing Research, 35, 913-920.

Gantz, B. J., Brown, C. J., \& Abbas, P. J. (1994). Intraoperative measures of electrically evoked auditory nerve compound action potential. American Journal of Otology, 15, 137-144.

Gantz, B. J., Tyler, R. S., Woodworth, G. G., Tye-Murray, N., \& Fryauf-Bertschy, H. (1994). Results of multichannel cochlear implants in congenital and acquired prelingual deafness in children: Five-year follow-up. The American Journal of Otology, 15 (Suppl. 2), 1-7.

Gantz, B. J., Woodworth, G. G., Knutson, J. F., Abbas, P. J., \& Tyler, R. S. (1993). Multivariate predictors of success with cochlear implants. In B. Fraysse, \& O. Deguine (Eds.), Cochlear implants: new perspectives (pp. 153-167). Basel: Karger.

Geers, A. E., \& Moog, J. S. (1991). Evaluating the benefits of cochlear implants in an education setting. American Journal of Otology, 12 (Suppl.), 116-125.

Geers, A., \& Moog, J. (1994). Description of the CID sensory aids study. The Volta Review, 96 (Monograph), 1-11.

Geier, L. L., \& Norton, S. J. (1992). The effects of limiting the number of Nucleus 22 cochlear implant electrodes programmed on speech perception. Ear and Hearing, 13, 340-348.

Lehnhardt, E., \& Aschendorff, A. (1993). Prognostic factors in 187 adults provided with the Nucleus Cochlear Mini-System 22. In B. Fraysse, \& O. Deguine (Eds.), Cochlear implants: new perspectives. Advances in Otorhinolaryngology, 48, 146-152, Basel: S Karger AG.

McKay, C. M., Vandali, A., McDermott, H.J., \& Clark, G. M. (1994). Speech processing for multichannel cochlear implants: Variations of the Spectral Maxima Sound Processor Strategy. Acta Otolaryngologica (Stockholm), 114, 52-58.

Mecklenburg, D. J. (1988). Cochlear implants in children: nonmedical considerations. American Journal of Otology, 9, 163168.

Miyamoto, R. T., Osberger, M. J., Robbins, A. M., Myres, W. A., \& Kessler, K. (1993). Prelingually deafened children's performance with the Nucleus multichannel cochlear implant. American Journal of Otology, 14, 437-445.

Nadol, J. B., Young, Y. S., \& Glynn, R. J. (1989). Survival of spiral ganglion cells in profound sensorineural hearing loss: Implications for cochlear implantation. Annals of Otology, Rhinology and Laryngology, 98, 411-416.

Osberger, M. J., Chute, P. M., Pope, M. L., Kessler, K., Carotta, C. C., First, J. B., \& Zimmerman-Phillips, S. (1991). Pediatric cochlear implant candidacy issues. American Journal of Otology, 12 (Suppl.), 80-88.

Osberger, M. J., Miyamoto, R. T., Zimmerman-Phillips, S., Lemink, J.L., Stroer, B. S., Firszt, J. B., \& Novak, M. A. (1991). 
Independent evaluation of the speech perception abilities of children with the Nucleus 22-channel cochlear implant system. Ear and Hearing, 12 (Suppl.), 66S-80S.

O'Sullivan, P. G., Ellul, S., Dowell, R. C., Pyman, B. C., \& Clark, G. M. (1997). The relationship between aetiology of hearing loss and outcome following cochlear implantation in a paediatric population. In G. M. Clark (Ed.), Cochlear implants: XVI World Congress of Otorhinolaryngology, Head and Neck Surgery (pp. 169-172). Bologna: Monduzzi Editore.

Parkin, J. L., Stewart, B. E., Dankowski, K., \& Haas, L.J. (1989). Prognosticating speech performance in multichannel cochlear implants. Otolaryngology Head and Neck Surgery, 101, 314319.

Peterson, G. E., \& Lehiste, I. (1962). Revised CNC lists for auditory tests. Journal of Speech and Hearing Disorders, 27, 62-70.

Pyman, P., Blamey, P., Lacy, P., Clark, G., \& Dowell, R. (2000). Development of speech perception in children using cochlear implants: Effects of etiology and delayed milestones. American Journal of Otology, 21, 57-61.

Quittner, A. L., \& Steck, J. T. (1991). Predictors of cochlear implant use in children. American Journal of Otology, 12 (Suppl.), 89-94.

Ryan, B. F., \& Joiner, B. L. (1994). Minitab handbook. Belmont, California: Wadsworth Publishing Company.

Sarant, J. Z., Blamey, P. J., Cowan, R. S. C., \& Clark, G. M. (1997). The effect of language knowledge on speech perception: What are we really assessing? The American Journal of Otology, 18, S135-S137.

Sarant, J. Z., Cowan, R. S. C., Blamey, P. J., Galvin, K. L., \& Clark, G. M. (1994). Cochlear implants for congenitally deaf adolescents: Is open-set speech perception a realistic expectation? Ear and Hearing, 15, 400-403.

Seghal, S. T., Kirk, I. L., Svirsky, M., \& Miyamoto, R. T. (1998). The effects of processor strategy on the speech perception performance of pediatric nucleus multichannel cochlear implant users. Ear and Hearing, 19, 149-161.

Shepherd, R. K., Hartmann, R., Heid, S., Hardie, N., \& Klinke, R. (1997). The central auditory system and auditory deprivation: Experience with cochlear implants in the congenitally deaf. Acta Otolarngologica (Stockholm), 532, 28-33.

Snik, A. F. M., Makhdoum, M. J. A., Vermeulen, A. M., Brokx, J. P. L., \& Van den Broek, P. (1997). The relation between age at the time of cochlear implantation and long-term speech perception abilities in congenitally deaf subjects. International Journal of Pediatric Otorhinolaryngology, 41, 121-131.

Somers, M. N. (1991). Speech perception abilities in children with cochlear implants or hearing aids. American Journal of Otology, 12 (Suppl.), 174-178.

Staller, S. J., Beiter, A. L., Brimacombe, J. A., Mecklenburg, D. J., $\&$ Arndt, P. A. (1991). Pediatric performance with the nucleus 22-channel cochlear implant system. American Journal of Otology, 12 (Suppl.), 126-136.

Stark, R. E. (1991). Speech-language habilitation of hearingimpaired children: basis for assessment and training. American Journal of Otology, 12 (Suppl.), 62-66.

Tong, Y. C., Busby, P. A., \& Clark, G. M. (1988). Perceptual studies on cochlear implant patients with early onset of profound hearing impairment prior to normal development of auditory, speech and language skills. Journal of the Acoustical Society of America, 84, 951-962.

Tong, Y. C., \& Clark, G. M. (1985). Absolute identification of electric pulse rates and electrode positions by cochlear implant patients. Journal of the Acoustical Society of America, 77, 1881-1888.

Van den Borne, B., Snik, A.F.M., Mens, L. H. M., Brokx, J. P. L., \& Van den Broek, P. (1996). Stapedius reflex measurements during surgery for cochlear implantation in children. American Journal of Otology, 17, 554-558.

Webster, D. B., \& Webster, M. (1977). Neonatal sound deprivation affects brain stem auditory nuclei. Archives of Otolaryngology, 103, 392-396.

Webster, D. B., \& Webster, M. (1979). Effects of neonatal conductive hearing loss on brainstem auditory nuclei. Annals of Otology, 88, 684-688.

\section{REFERENCE Notes}

1. Haskins, J. (1949). A Phonetically Balanced Test of Speech Discrimination for Children. Unpublished Master's Dissertation, Northwestern University.

2. Zwolan, T. A. (1995). Factors affecting auditory performance with a cochlear implant by prelingually deafened adults. 100th NIH Consensus Development Conference on Cochlear Implants in Adults and Children, May 15-17. 


\section{University Library}

\section{- M M N E R VA A gateway to Melbourne's research publications}

Minerva Access is the Institutional Repository of The University of Melbourne

Author/s:

Sarant, JZ;Blamey, PJ;Dowell, RC;Clark, GM;Gibson, WPR

Title:

Variation in speech perception scores among children with cochlear implants

Date:

2001-02-01

Citation:

Sarant, J. Z., Blamey, P. J., Dowell, R. C., Clark, G. M. \& Gibson, W. P. R. (2001). Variation in speech perception scores among children with cochlear implants. EAR AND HEARING, 22 (1), pp.18-28. https://doi.org/10.1097/00003446-200102000-00003.

Persistent Link:

http://hdl.handle.net/11343/27590 